\title{
An Application of TOPSIS Approach in Determination of Spread Influencers in a Competitive Industrial Space: Evidence from the Banking Network of Ghana
}

\author{
Yusheng Kong1, Alex Boadi Dankyi ${ }^{*}$, Evans Takyi Ankomah-Asare ${ }^{1}$, Antoinette Asabea Addo ${ }^{2}$ \\ ${ }^{1}$ School of Finance and Economics, Jiangsu University, Zhenjiang, China \\ ${ }^{2}$ School of Public Administration, Jiangsu University, Zhenjiang, China \\ Email: yshkong@ujs.edu.cn, ^alexboadidankyi@stmail.ujs.edu.cn, e.takyi@ujs.edu.cn, asabeaaddoa@stmail.ujs.edu.cn
}

How to cite this paper: Kong, Y.S., Dankyi, A.B., Ankomah-Asare, E.T. and Addo, A.A. (2019) An Application of TOPSIS Approach in Determination of Spread Influencers in a Competitive Industrial Space: Evidence from the Banking Network of Ghana. Journal of Human Resource and Sustainability Studies, 7, 312-327. https://doi.org/10.4236/jhrss.2019.72020

Received: May 21, 2019

Accepted: June 21, 201

Published: June 26, 2019

Copyright $\odot 2019$ by author(s) and Scientific Research Publishing Inc. This work is licensed under the Creative Commons Attribution International License (CC BY 4.0).

http://creativecommons.org/licenses/by/4.0/

\begin{abstract}
In this paper, we investigated into aggregated social influence. We adopted and modified the weighted TOPSIS approach to ascertain the overall social influences of management members in the banking network of Ghana. The weighted TOPSIS method employs a composite approach of classical centrality influence that uses the position of the actor in the network hierarchy, the intensity of his interaction, extent of his connectivity and flow of information within the network. The approach offers an extensive advantage in ensuring holistic decision making by implementing an algorithm that employs a multi-criteria approach. The study revealed that although most single attributes were significant in measuring the niched aspect of social influence, the closeness to ideal that was attained through a weighted TOPSIS algorithm showed stronger ties and was conclusive enough to judge the social influence of actors to warrant its sole application in the determination of spreaders or influential nodes in a network. To enhance efficiency in decision making in relation to employment and layoffs, it is recommended that a social network analysis which adapts a multi-attribute decision-making approach that reflects both individual strength and weaknesses in totality for all aspect of social influences should be employed. We recommend further studies into Actor Ranking and its impact on recruitment practices for organizational innovation.
\end{abstract}

\section{Keywords}

Social Network Analysis, TOPSIS, Banking Network, Human Capital, Centrality Measures 


\section{Introduction}

Efficiencies in organizational operations in competitive markets are of key interest to all organizations in recent times. Subsequently, organizations make decisions in the areas of employment and downsizing through layoffs in an attempt to remain viable in competitive markets [1]. Employment and downsizing can reduce the cost of doing business but may yield less than desired results if not properly executed. The intent of human resource managers and recruiters in employing or downsizing is to enhance their strategic positions by reducing the cost of doing business while retaining core competencies and desired skill sets of the surviving members of the organization.

Clandestinely, the sustainable growth of an organization is dependent on the ability of the current employees that possess the required human capital to pass it on to new and old employees alike that do not possess this required human capital. Thus, diffusion of this specialized knowledge, skills, ideas, and experiences is per scientific principles from a higher concentration area to a lower concentration area [2] [3] [4].

Human Resource Managers and Recruiters in general are therefore in more recent times challenged with the responsibility to improve if not optimizing their recruiting practices and succession planning for competitive advantage. In today's increasingly knowledge-based economy, effective recruitment is likely to be the most critical human resource function for organizational success and survival [5]. Carol [6] adds that recruitment strategies in human resource management both internally and externally are focused on strengthening competitive advantage by assembling the best and most influential human capital in achieving organizational goals and remaining competitive enough in maintaining or increasing market shares. Mostly, recruiters target influential nodes or spreaders in the quest to gain a competitive advantage in their market space. It is important to establish that the possession on a high human capital alone is not enough to ensure the transfer of these skills, knowledge, ideas, and experiences but also the role and relevance of the actor in terms of the transfer of human capital.

The challenging economic conditions push organizations to resort to downsizing which alters operations to remain competitive. Globally, organizations in almost every industry use downsizing to maximize efficiencies, reduce operating costs and increase profits as part of strategic planning. Surviving employees are integral to organizational success. If management of downsizing organizations is to achieve desired results of layoffs, surviving employees' skill set and organizational commitment must remain intact [7]; otherwise, employees whom organizations' rely on driving revitalization may not possess the required human capital partly because layoffs can negatively affect influencers or pillars of the organizational success. Any loss of talent may minimize the expected benefits of layoffs.

Employees are social beings who tie and break social links over time and space. Social links may be in the form of family, friends, colleagues, teachers, among others. Through this links and interactions, employees influence and 
change the ideas, skills, knowledge, experiences, etc of each other. A colleague at work sharing his or her experience on the usage of new technology and how to overcome the challenges associated with the user may influence others acceptance or rejection of this technology. Further, sharing ideas on a new project under implementation in one's organization in a professional association group impacts on its adaptation and implementation in other organizations in the future. Aşcı, Tan [8] viewed the concept of social learning as the effective way of ensuring the sustainability of a society's growth that occurs through social interactions and processes between actors within a social network, either through direct or indirect interaction. The efficacy of the social learning theory has been well established in recent studies provoking the interest of researchers in the application of social network theories in business studies. Employees influence, inspire and learn from each other and its resultant, latent cooperation that can be observed in social networks, where interacting users are connected with each other. Studies have established that nodes do not have the same importance in a network and therefore it is important to rank nodes. In the field of human resource management, the removal or addition of an employee (hiring, retirement, transfer, resignation or dismissal) can cause the collapse or malfunction of the network. Thus, some employees control the stability and competitive advantage that an organization enjoys in a competitive industrial space. The scarcity and competitiveness of the labour market swing organizations to make attempts to determine a set of employees who can diffuse [9] knowledge, skills, ideas that offer a competitive advantage through social networks. Consequently, the number of people one can influence or be influenced by to adopt or learn a new knowledge coupled with the quality of knowledge possessed by the influencer is important for competitive advantage.

This study investigated into aggregate social importance of a node premising from an optimal point of view of each node in their importance in the various centrality measures thereby identifying the most important spreaders in a competitive network space. It will employ a multi-attribute decision making model in this respect. Again, the study will assess the correlation between the TOPSIS determined importance (closeness to aggregated ideal) and other single attributes determined importance and finally, we will apply the TOPSIS weighted importance to the banking network of management in the Ghanaian developing economy.

\section{Literature Review and Theories}

\subsection{Centrality Measures}

Many researchers have keenly researched into the social interactions basically on the characteristics of actors or nodes and the edges or ties strength. The two characteristics are manipulated through various approaches in ranking or identifying influential nodes to help the spread of knowledge, skills, and ideas. Different approaches have been put forward in the determination of important 
nodes. The most classical approach is the centrality measures [10]. Each centrality measure proposed or adopted to investigate the importance of nodes in a social network is done from a particular point of view [11] [12]. Degree centrality, for instance, assesses the importance of nodes base on the quantitative connectivity, even within the degree in a directed network, there are indegree centrality and outdegree centrality where importance is measured based on quantification of in and out connectivity [10]. Chuluun, Prevost [13]. Landherr, Friedl [14] in a critical review of centrality measures explained that Closeness centrality measures the average length of the shortest path between the node and all other nodes in the graph. Accordingly, the more central a node is, the closer it is to all other nodes in the network. Another centrality measure is Betweenness centrality which quantifies the number of times a node acts as a bridge along the shortest paths between two other nodes. Bonacich [15] explained Eigenvector centrality as a measure of the influence of a node in a network by assigning relative scores to all nodes in the network based on the assumption that connection to high-scoring nodes contributes more to the node in question than equal connections to low-scoring nodes. Additionally, Information centrality assesses how central a node is in terms of information spread within a network. These and many other centralities are targeted at a specific dimension of importance in a network.

\subsection{Human Capital Transfer}

Organizations through various approaches transfer their knowledge both explicit and tacit to their employees to niche their portion in the competitive industrial space. This transfer process comes in forms such as inter-organizational, inter-unit or groups in the same organization, or within members or actors in an organization [5] [16] [17]. The conditions of transfers are hinged on diffusion and communication processes. Firstly, highly concentrated employees attempt to organize, create, capture or spread knowledge, skills, ideas, and experiences (human capital) to other employees who do not possess or possess but inadequate to meet sustainability levels for future usage. Secondly, human capital transfer process usually is very similar to a communication process that occurs between two entities just as in the case of diffusion [18]. Dass and Chelliah [18] opine that Human Capital transfer is of major concern to all organizations because of its time-bound relevance. Organizations, therefore, employ both the "make" and "buy" succession planning strategies to remain relevant and competitive in the industrial space. Thus, the timing of the transfer of human capital to keep employees and the organization innovative, productive and competitive is as important as the human capital hub [19]. This has informed human resource policies and practices.

\subsection{Multi Attribute Decision Making and Topsis}

Humans as social beings are always faced with choices to be made from a num- 
ber of options. Multi-attribute decision making (MADM) deals with situations in which a decision maker has to make a choice out of a set of choices, based on information about these choices on a number of attributes. Multi-attribute decision making gives decision makers' the opportunity to maximize the process of decision making in such a way that all relevant and available information is used and integrated in order to arrive at a preference order of the choices [20] [21].

One approach rationally adopted in multi-attribute decision making options is the Technique for Order of Preference by Similarity to Ideal Solution (TOPSIS) [22] [23] [24]. TOPSIS method minimizes the distance to the ideal solution while the distance to the lowest point is maximized and uses a compensatory accumulation method that evaluates several choices by considering the weighted criteria. The Technique for Order Preference by Similarity to Ideal Solution (TOPSIS) is extremely beneficial when a decision-making process is complex. The reason is that TOPSIS can prioritize multiple-choice criteria into a hierarchy by assessing the relative importance of criteria and can thus generate an overall ranking of the alternatives.

TOPSIS has been applied in so many studies in different disciplines. Business studies [23] [25] [26] [27] [28], Ecological studies [29] [30], Aviation studies [31], Mathematical sciences [32] and Engineering [33] [34].

\section{Methodology}

For the purpose of this study, 6 commercial banks listed on the Ghana Stock Exchange (GSE) will be employed. Only Banks listed and operating in Ghana were considered, Table 1 shows the listed banks operating in Ghana from which data was collected. The Banks were Access Bank, Agricultural Development Bank, EcoBank, GCB Bank Limited, Republic Bank formerly HFC Bank Ghana Limited, and Standard Chartered Bank Ghana Limited. The aggregated management strength of all six Banks was 64 . Data were extrapolated from the curriculum vitae of actors, as well as industrial reports. The UCINET 6 for Windows version 6.658 and Excel was used as the analytical tool for the network.

Table 1. Listed Banks and Management team size

\begin{tabular}{ccc}
\hline No. & Banks in 2019 & Management team size \\
\hline 1 & Access Bank & 11 \\
2 & ADB Bank Limited & 13 \\
3 & Ecobank Ghana Limited & 7 \\
4 & GCB Bank Limited & 13 \\
5 & Republic Bank (HFC Bank Ghana Limited) & 9 \\
6 & Standard Chartered Bank Ghana Limited & 11 \\
& Total & 64 \\
\hline
\end{tabular}

Source: (Wikipedia, 2019) and field data 2019 
Table 2 represents the variables weight determination for the network. The aggregated value of an individual based on the variables of assessment as determined in Table 2 is $Z_{v}=\sum_{v}^{n}(S+B+E+A+P)$ where

Table 2. variable weight determination.

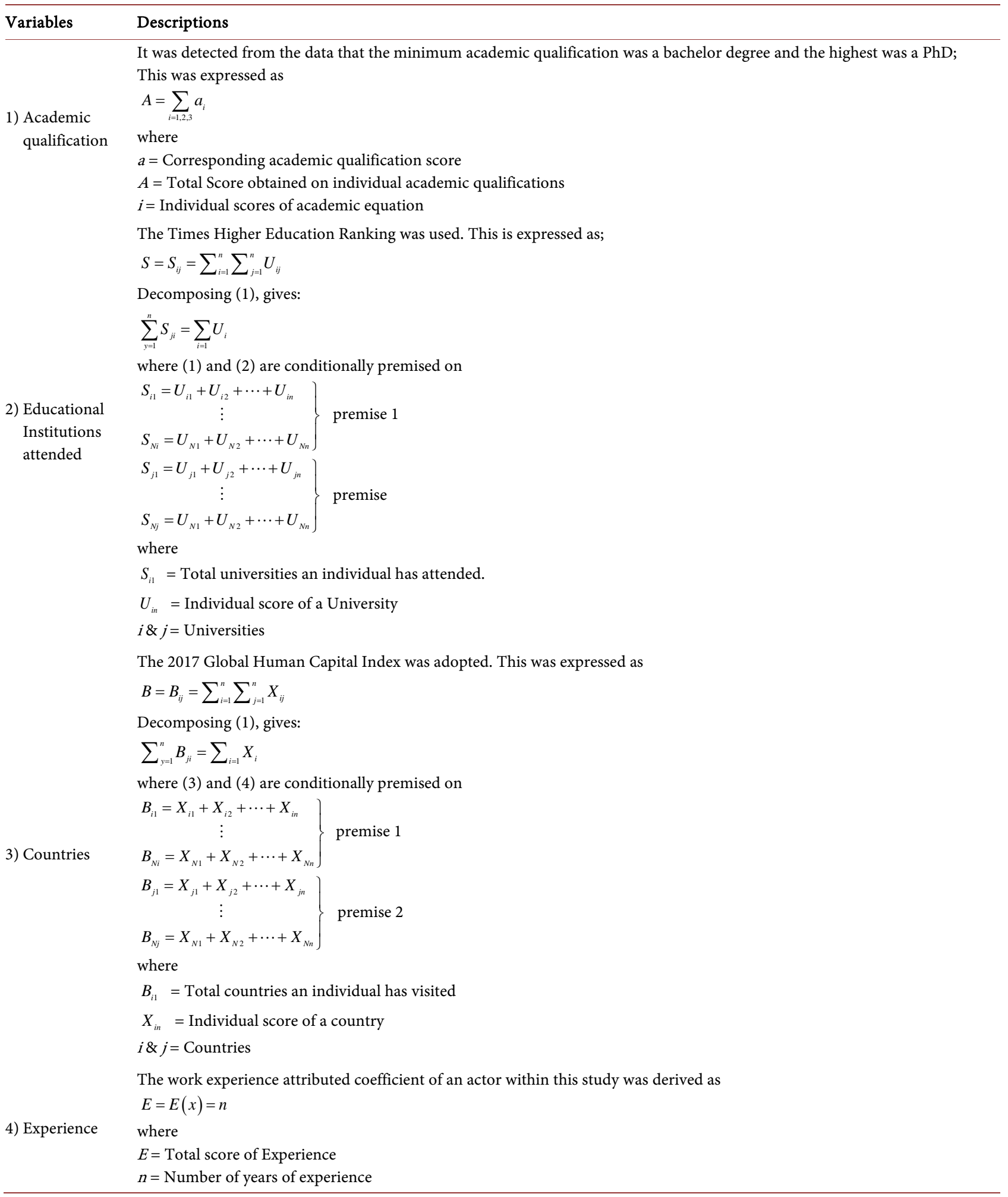




\section{Continued}

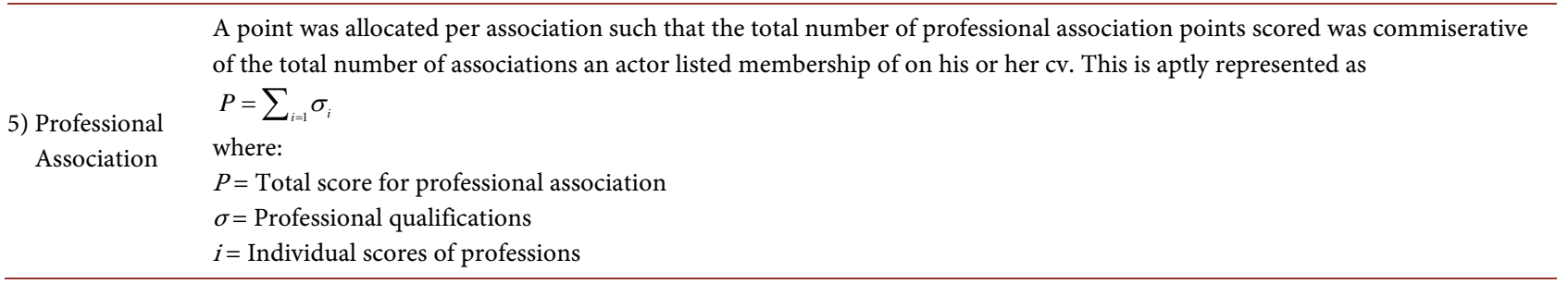

$Z=$ The individual employee' cumulative HC;

$S=$ Post-secondary educational institutions;

$B=$ Countries;

$E=$ Experience;

$A=$ Academic qualification;

$P=$ Professional association.

The weight of the actors was infused in the development of the network. The condition for interaction between actors in a network has always been contingent on proximity (closeness, distance) and accessibility (centrality) and similarities (clusters). The argument is that all things being equal, proximity, accessibility, and similarities are catalysts for establishing relationships between actors within a network. The network was undirected in nature as sharing of knowledge in an organization takes both formal and informal thereby given little credence to the direction.

\section{Our Approach}

We approached our study following the outlined steps in Figure 1.

Actors within a complex network in a competitive industrial space do not have the same influence on the systems. Competitive advantage is affected by the ability of actors to influence phenomena or other actors within the network spaces. Researchers have combined ordinary differential approaches to explain how network metrics can be used to explain the interactive strength of actors within complex networks. The metrics of the network analysis, then serve as the basis for understanding the impact, role and relevance of actors within complex spaces [13] [14] [34] [35] [36] [37] [38].

A weighted TOPSIS approach will be employed to ascertain the actor's influence and proportional control of human capital in the banking network. The data to be obtained from the banking network $E_{i, j}$ and with the connection contingencies made up of centrality matrix $M=\left(E_{m n}\right)$ such that $M$ is composed of all the diffusion and adoption parameters that $i$ and $j$ depend on to build dyadic relations. Normalizing this will allow $M$ to be written as

$$
M=r_{i j}=\frac{E_{m n}}{\sqrt{\sum_{i}^{m} E_{i j}^{2}}}, i=1, \cdots m ; j=1 \cdots, n \quad \text { Equation (1) }
$$

Thus, by multiplying the columns of the obtained normalized matrix by the determined weight of the interaction between actors $i$ and $j$, a new decision ma- 
trix $K=\left(k_{m n}\right)$ is obtained such that a new network $F_{i, j}$ is developed with a weighted $w$ matrix

$$
F=h_{i j}=w_{j} \times r_{i j}, i=1, \cdots, m^{\prime} j=1, \cdots, n
$$

But $w_{j}=\frac{1}{n}$ and the weight of $j$ actors remain same.

Further, to deduce our positive and negative ideal influencers within the banking network, the study will denote the positive ideal as $A^{+}$and the negative ideal as $A^{-}$. Referencing the approach by Liao, Mariani [39].

$$
\begin{aligned}
& A^{+}=\left\{h_{1}^{+}, h_{2}^{+}, \cdots h_{n}^{+}\right\}=\left\{\left({ }_{i}^{\max } P / j \in K_{b}\right)\left({ }_{i}^{\max } P / j \in K_{c}\right)\right\} \quad \text { Equation (3) } \\
& A^{-}=\left\{h_{1}^{-}, h_{2}^{-}, \cdots h_{n}^{-}\right\}=\left\{\left({ }_{i}^{\max } P / j \in K_{b}\right)\left({ }_{i}^{\max } P / j \in K_{c}\right)\right\} \text { Equation (4) }
\end{aligned}
$$

Thus, by considering the separation condition of $S$, such that $S_{i}^{+}$is reminiscent of actor $i^{\prime} s$ decision that is closer to $A^{+}$while $S_{i}^{-}$reflects close proximity to $A^{-}$allow us to measure actor importance in the banking network as reflected by their relative closeness to ideal human capital diffusion and adoption and is reflected in

$$
\begin{array}{cl}
S_{i}^{+}=\sqrt{\sum_{j=1}^{n}\left(h_{j}^{+}-h_{i j}\right)^{2}, i=1, \cdots m ; j=1, \cdots, n} & \text { Equation (5) } \\
S_{i}^{-}=\sqrt{\sum_{j=1}^{n}\left(h_{j}^{-}-h_{i j}\right)^{2}, i=1, \cdots m ; j=1, \cdots, n} & \text { Equation (6) }
\end{array}
$$

Finally, the relative closeness to the idea solution $S$ as a means of determining influential diffusers can be derived from Equation (5) and Equation (6) as

$$
Q_{i}=\frac{S_{i}^{-}}{S_{i}^{-}+S_{i}^{+}}, i=1, \cdots, m
$$

The final output from Equation (8) will then be ranked and used as the optimal influence of industry and actors in the network.

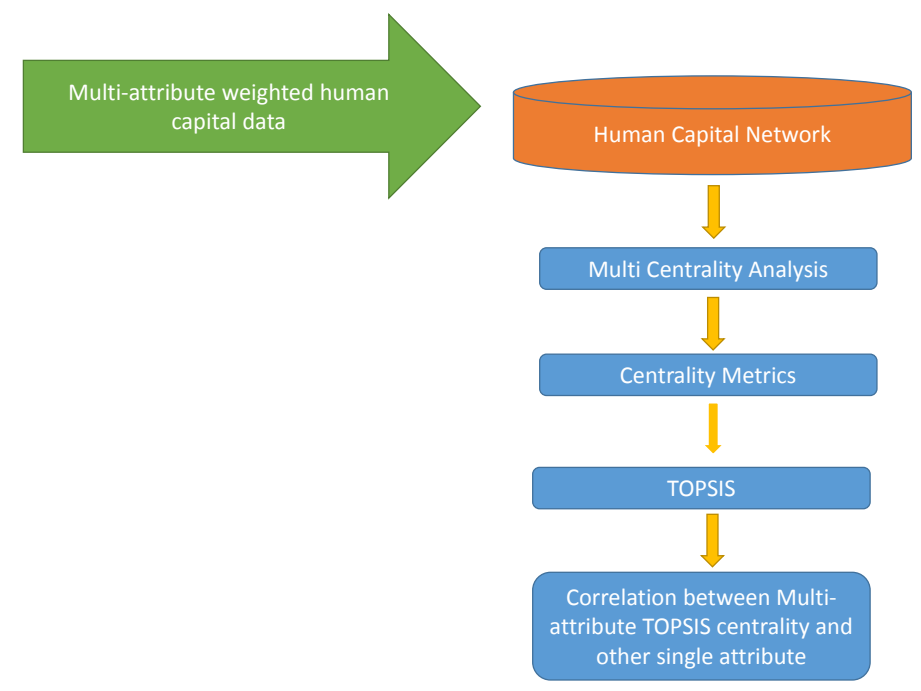

Figure 1. Study outline. 


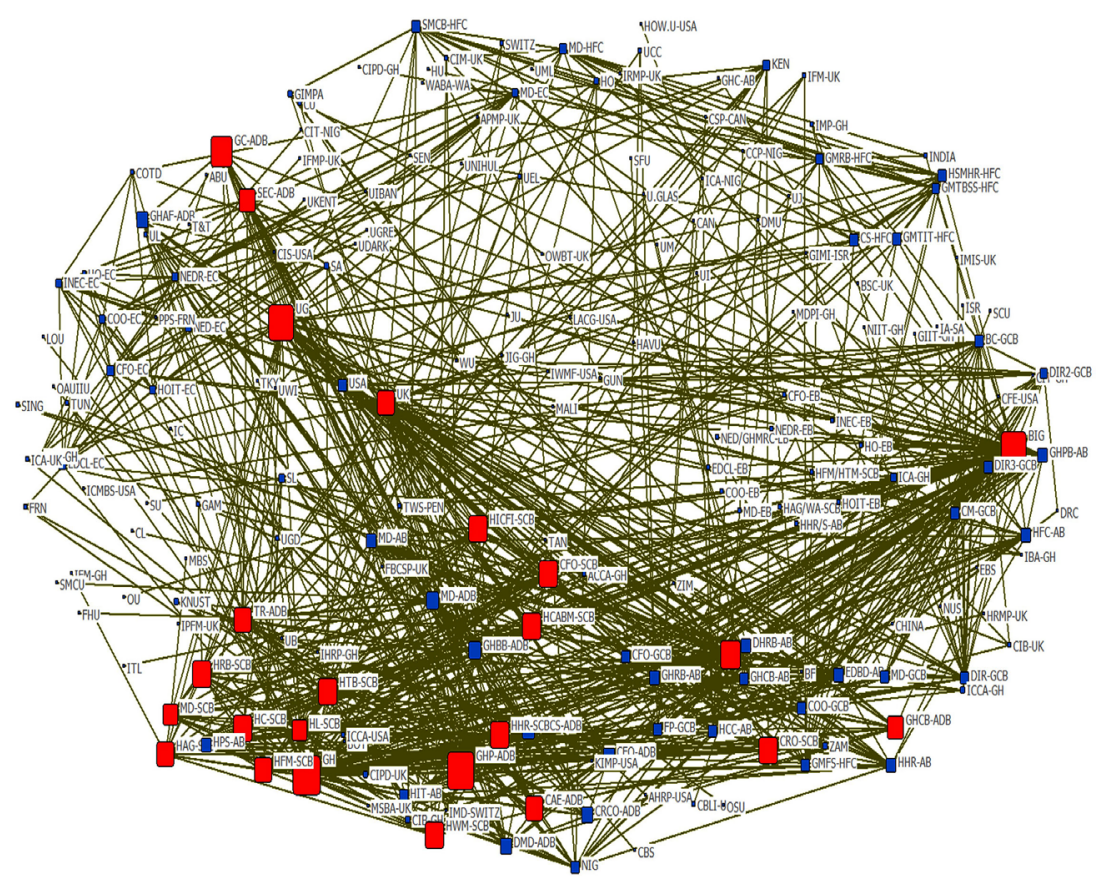

Figure 2. Weighted TOPSIS financial network.

Figure 2 represents the network of the banking industries based on the weighted attributes from the TOPSIS run algorithms.

\section{Results}

Table 3 represents the centrality measures and actor ranking of importance in each measure. From a glance, there is a significant difference between actors and their importance in the different individual importance measures. From Table 3, CRO-SCB ranked first in Degree Centrality, $17^{\text {th }}$ in Closeness Centrality and second $\left(2^{\text {nd }}\right)$ in Closeness to Ideal Centrality. Further HO-EC who ranked least, $64^{\text {th }}$, in the Closeness to Ideal Centrality the rank improved to $47^{\text {th }}$ position. Still in Table 3, MD-SCB ranked $39^{\text {th }}$ position in terms of Betweenness Centrality, $25^{\text {th }}$ in Closeness Centrality but ranked first in the Closeness to Ideal Centrality that takes into consideration the totality of centralities in relation to the ideal situation ranking. The DIR-GCB ranked $22^{\text {nd }}$ in both Eigenvector Centrality and Information Centrality, First $\left(1^{\text {st }}\right)$ in Closeness and Betweeness Centralities but ranked $4^{\text {th }}$ in the Closeness to Ideal Centrality.

In summary from Table 3, a microscopic view establishes the significance of an aggregated social influence as actors took different ranks in different measures. For instance, the Managing Director of SCB (MD-SCB) was ranked as the most influential $\left(1^{\text {st }}\right)$ in the closeness to the ideal that is the aggregation of all the other measures considering the strength and weaknesses of actors in optimizing their rank but $39^{\text {th }}$ out of 64 actors in the banking network. This finding strongly aligns with Muruganantham and Gandhi [40] which suggests that a multi-attribute TOPSIS rated decision making employs efficiencies that reduces errors of judgement. 
Table 3. Centrality measures and rankings.

\begin{tabular}{|c|c|c|c|c|c|c|c|c|c|c|c|c|}
\hline Actor & DC & DCRank & EVC & EVCRank & $\mathrm{CC}$ & CCRank & BC & BCRank & IC & ICRank & CI & CIRank \\
\hline BC-GCB & 0.059 & 10 & 0.056 & 26 & 0.436 & 2 & 5 & 3 & 2.68 & 15 & 0.43 & 18 \\
\hline CAE-ADB & 0.031 & 44 & 0.042 & 38 & 0.421 & 37 & 0.353 & 55 & 2.56 & 41 & 0.29 & 48 \\
\hline CFO-ADB & 0.031 & 44 & 0.037 & 47 & 0.421 & 37 & 1.258 & 37 & 2.535 & 46 & 0.28 & 52 \\
\hline CFO-EC & 0.039 & 34 & 0.049 & 32 & 0.394 & 56 & 1.444 & 34 & 2.595 & 32 & 0.41 & 22 \\
\hline CFO-GCB & 0.028 & 50 & 0.037 & 47 & 0.43 & 8 & 0.577 & 50 & 2.528 & 48 & 0.29 & 51 \\
\hline CFO-SCB & 0.05 & 20 & 0.189 & 9 & 0.424 & 27 & 0.663 & 46 & 2.683 & 14 & 0.37 & 36 \\
\hline CIO-SCB & 0.094 & 3 & 0.27 & 3 & 0.43 & 8 & 2.058 & 23 & 2.774 & 2 & 0.49 & 3 \\
\hline CM-GCB & 0.023 & 56 & 0.029 & 55 & 0.428 & 18 & 0.284 & 57 & 2.452 & 56 & 0.20 & 61 \\
\hline COO-EC & 0.041 & 31 & 0.038 & 45 & 0.394 & 56 & 2.308 & 17 & 2.567 & 40 & 0.43 & 16 \\
\hline COO-GCB & 0.034 & 41 & 0.044 & 34 & 0.43 & 8 & 1.246 & 38 & 2.569 & 38 & 0.38 & 31 \\
\hline CRCO-ADB & 0.053 & 18 & 0.055 & 27 & 0.423 & 32 & 2.626 & 15 & 2.658 & 20 & 0.42 & 21 \\
\hline CRO-SCB & 0.105 & 1 & 0.303 & 2 & 0.429 & 17 & 3.434 & 10 & 2.773 & 3 & 0.53 & 2 \\
\hline CS-HFC & 0.021 & 61 & 0.027 & 59 & 0.412 & 51 & 0.603 & 49 & 2.411 & 60 & 0.30 & 46 \\
\hline DHRB-AB & 0.041 & 31 & 0.057 & 24 & 0.43 & 8 & 2.154 & 19 & 2.621 & 29 & 0.37 & 35 \\
\hline DIR2-GCB & 0.051 & 19 & 0.07 & 17 & 0.432 & 4 & 4.932 & 4 & 2.717 & 5 & 0.44 & 9 \\
\hline DIR3-GCB & 0.047 & 24 & 0.05 & 30 & 0.432 & 4 & 2.796 & 13 & 2.617 & 30 & 0.43 & 17 \\
\hline DIR-GCB & 0.087 & 4 & 0.059 & 22 & 0.44 & 1 & 9.656 & 1 & 2.652 & 22 & 0.49 & 4 \\
\hline DMD-ADB & 0.059 & 10 & 0.062 & 21 & 0.423 & 32 & 2.33 & 16 & 2.687 & 13 & 0.44 & 8 \\
\hline EDBD-AB & 0.055 & 14 & 0.066 & 20 & 0.43 & 8 & 3.399 & 11 & 2.671 & 18 & 0.44 & 11 \\
\hline EDCL-EC & 0.028 & 50 & 0.03 & 53 & 0.392 & 62 & 0.611 & 48 & 2.488 & 52 & 0.30 & 43 \\
\hline FP-GCB & 0.028 & 50 & 0.035 & 51 & 0.43 & 8 & 3.06 & 12 & 2.48 & 53 & 0.30 & 45 \\
\hline GC-ADB & 0.025 & 55 & 0.029 & 55 & 0.419 & 41 & 0.231 & 59 & 2.473 & 55 & 0.20 & 62 \\
\hline GHAF-ADB & 0.03 & 48 & 0.033 & 52 & 0.419 & 41 & 0.17 & 61 & 2.528 & 48 & 0.18 & 63 \\
\hline GHBB-ADB & 0.055 & 14 & 0.067 & 18 & 0.424 & 27 & 1.004 & 42 & 2.69 & 11 & 0.40 & 25 \\
\hline GHCB-AB & 0.048 & 21 & 0.057 & 24 & 0.43 & 8 & 0 & 63 & 2.657 & 21 & 0.41 & 23 \\
\hline GHCB-ADB & 0.023 & 56 & 0.027 & 59 & 0.419 & 41 & 1.963 & 25 & 2.442 & 58 & 0.18 & 64 \\
\hline GHCS-ADB & 0.031 & 44 & 0.041 & 41 & 0.421 & 37 & 1.345 & 36 & 2.544 & 43 & 0.29 & 49 \\
\hline GHP-ADB & 0.032 & 43 & 0.036 & 50 & 0.421 & 37 & 0.844 & 44 & 2.552 & 42 & 0.28 & 54 \\
\hline GHPB-AB & 0.048 & 21 & 0.058 & 23 & 0.432 & 4 & 4.571 & 5 & 2.639 & 26 & 0.37 & 34 \\
\hline GHRB-AB & 0.042 & 29 & 0.052 & 29 & 0.43 & 8 & 1.418 & 35 & 2.635 & 27 & 0.37 & 33 \\
\hline GMFS-HFC & 0.039 & 34 & 0.044 & 34 & 0.417 & 46 & 3.646 & 9 & 2.576 & 36 & 0.37 & 32 \\
\hline GMRB-HFC & 0.021 & 61 & 0.02 & 63 & 0.412 & 51 & 1.02 & 41 & 2.388 & 61 & 0.31 & 42 \\
\hline GMTBSS-HFC & 0.022 & 59 & 0.022 & 62 & 0.412 & 51 & 2.235 & 18 & 2.375 & 62 & 0.32 & 40 \\
\hline GMTIT-HFC & 0.026 & 54 & 0.039 & 43 & 0.412 & 51 & 1.17 & 40 & 2.477 & 54 & 0.36 & 37 \\
\hline HAG-SCB & 0.054 & 16 & 0.188 & 10 & 0.414 & 47 & 1.621 & 31 & 2.677 & 16 & 0.39 & 29 \\
\hline HCABM-SCB & 0.044 & 26 & 0.198 & 7 & 0.424 & 27 & 1.748 & 26 & 2.691 & 10 & 0.27 & 59 \\
\hline HCC-AB & 0.039 & 34 & 0.17 & 14 & 0.43 & 8 & 4.092 & 8 & 2.643 & 24 & 0.34 & 38 \\
\hline
\end{tabular}


Continued

\begin{tabular}{|c|c|c|c|c|c|c|c|c|c|c|c|c|}
\hline HC-SCB & 0.054 & 16 & 0.046 & 33 & 0.425 & 25 & 0.52 & 52 & 2.577 & 35 & 0.39 & 27 \\
\hline HFC-AB & 0.031 & 44 & 0.044 & 34 & 0.428 & 18 & 2.094 & 21 & 2.541 & 44 & 0.28 & 53 \\
\hline HFM-SCB & 0.062 & 7 & 0.21 & 6 & 0.414 & 47 & 0.768 & 45 & 2.712 & 7 & 0.44 & 14 \\
\hline HHR-AB & 0.056 & 13 & 0.071 & 16 & 0.419 & 41 & 1.655 & 29 & 2.69 & 11 & 0.45 & 7 \\
\hline HHR-SCB & 0.043 & 27 & 0.173 & 12 & 0.423 & 32 & 0.256 & 58 & 2.643 & 24 & 0.28 & 56 \\
\hline HICFI-SCB & 0.048 & 21 & 0.183 & 11 & 0.424 & 27 & 0.487 & 53 & 2.674 & 17 & 0.34 & 39 \\
\hline HIT-AB & 0.03 & 48 & 0.039 & 43 & 0.427 & 20 & 2.078 & 22 & 2.523 & 50 & 0.29 & 50 \\
\hline HL-SCB & 0.068 & 6 & 0.221 & 4 & 0.427 & 20 & 1.611 & 32 & 2.736 & 4 & 0.43 & 15 \\
\hline HO-EC & 0.02 & 64 & 0.015 & 64 & 0.293 & 64 & 0 & 63 & 2.355 & 64 & 0.29 & 47 \\
\hline HOIT-EC & 0.037 & 38 & 0.04 & 42 & 0.392 & 62 & 0.289 & 56 & 2.576 & 36 & 0.44 & 10 \\
\hline HPS-AB & 0.028 & 50 & 0.042 & 38 & 0.426 & 22 & 0.091 & 62 & 2.529 & 47 & 0.27 & 58 \\
\hline HRB-SCB & 0.062 & 7 & 0.214 & 5 & 0.426 & 22 & 1.623 & 30 & 2.713 & 6 & 0.42 & 20 \\
\hline HSMHR-HFC & 0.021 & 61 & 0.028 & 58 & 0.412 & 51 & 2.056 & 24 & 2.371 & 63 & 0.31 & 41 \\
\hline HTB-SCB & 0.058 & 12 & 0.193 & 8 & 0.426 & 22 & 1.73 & 27 & 2.706 & 8 & 0.40 & 26 \\
\hline HWM-SCB & 0.043 & 27 & 0.172 & 13 & 0.423 & 32 & 0.432 & 54 & 2.644 & 23 & 0.28 & 57 \\
\hline INEC-EC & 0.047 & 24 & 0.05 & 30 & 0.394 & 56 & 0.848 & 43 & 2.628 & 28 & 0.46 & 6 \\
\hline $\mathrm{MD}-\mathrm{AB}$ & 0.071 & 5 & 0.073 & 15 & 0.433 & 3 & 5.57 & 2 & 2.702 & 9 & 0.46 & 5 \\
\hline MD-ADB & 0.061 & 9 & 0.067 & 18 & 0.424 & 27 & 4.417 & 6 & 2.671 & 18 & 0.44 & 11 \\
\hline MD-EC & 0.041 & 31 & 0.044 & 34 & 0.394 & 56 & 1.721 & 28 & 2.589 & 33 & 0.41 & 24 \\
\hline MD-GCB & 0.039 & 34 & 0.054 & 28 & 0.431 & 7 & 1.482 & 33 & 2.617 & 30 & 0.39 & 28 \\
\hline MD-HFC & 0.037 & 38 & 0.038 & 45 & 0.413 & 49 & 2.124 & 20 & 2.54 & 45 & 0.43 & 19 \\
\hline MD-SCB & 0.101 & 2 & 0.334 & 1 & 0.425 & 25 & 1.21 & 39 & 2.783 & 1 & 0.57 & 1 \\
\hline NED-EC & 0.042 & 29 & 0.037 & 47 & 0.394 & 56 & 2.657 & 14 & 2.586 & 34 & 0.44 & 13 \\
\hline NEDR-EC & 0.036 & 40 & 0.03 & 53 & 0.394 & 56 & 4.148 & 7 & 2.502 & 51 & 0.38 & 30 \\
\hline SEC-ADB & 0.022 & 59 & 0.027 & 59 & 0.419 & 41 & 0.231 & 59 & 2.426 & 59 & 0.21 & 60 \\
\hline SMCB-HFC & 0.023 & 56 & 0.029 & 55 & 0.413 & 49 & 0.544 & 51 & 2.446 & 57 & 0.30 & 44 \\
\hline TR-ADB & 0.033 & 42 & 0.042 & 38 & 0.422 & 36 & 0.648 & 47 & 2.569 & 38 & 0.28 & 55 \\
\hline
\end{tabular}

Degree Centrality (DC), Eigenvector Centrality (EVC), Closeness Centrality (CC), Betweenness Centrality (CB), Information Centrality (IC), Closeness to ideal (CI).

Table 4 shows correlational studies of the raw scores from the field to the various centrality measures. From Table 4, the correlation of the various centrality with the field data is assessed. Closeness centrality and Betweeness centrality was not significant with correlation of 0.14 and 0.44 respectively. Closeness to Ideal Centrality, Information Centrality, Eigenvector Centrality and Degree Centrality were significantly correlational with the field data of the managers. Ranking the correlational strength from the least to most significant, the centrality measures of Eigenvector was the least with 0.53 , followed by Information centrality with 0.75 , Degree Centrality with 0.88 and Closeness to ideal centrality showing the most correlational with the data. 
Table 4. Correlation of centrality measures and field data.

\begin{tabular}{cccccc}
\hline CI & IC & BC & CC & EVC & DC \\
\hline 0.98 & 0.75 & 0.44 & 0.14 & 0.53 & 0.88 \\
\hline
\end{tabular}

Degree Centrality (DC), Eigenvector Centrality (EVC), Closeness Centrality (CC), Betweenness Centrality (CB), Information Centrality (IC), Closeness to ideal (CI).

In summary from Table 4, although most of the measures had a strong correlation with the field data, the closeness to ideal measure had a stronger correlation. From the results, it is justifiable to use the Closeness to Ideal centrality ranking in social network analysis as suggested by Chou, Yen [27] because it does not only correlate but shows a stronger correlation to the field data as compared to any of the single attribute decision making measures. It therefore accounts for the diversity of strength in actors in decision making.

\section{Conclusions}

Previous studies on ranking influential actors within networks have predominantly focused on individual centrality measures such as Degree centrality, Closeness Centrality, Information Centrality, Betweeness Centrality and Eigenvector Centrality [41], which overlook a unifying ground for the different purpose driven centrality measures. In the view of Rossi, Blake [38] decision making with single attributes turns to side-line of the importance of other equally significant measures in determining worker relevance. The emergence of different measures of influence in social network analysis is the conviction of the unreliableness of the individual measures of centrality in reaching universal reliability as suggested by Deng, Yeh [25] [42]. It was therefore, important to look at a broader and an all-inclusive methodology of ranking spreaders in social networks.

The results in this study revealed that, although most single attributes were significant in measuring the niched aspect of social influence, the closeness to ideal that was attained through a weighted TOPSIS algorithm showed stronger ties and was conclusive enough to judge the social influence of actors to warrant its sole application in the determination of spreaders or influential nodes in a network. Again, the comparative analysis of the various individual ranking indicated that the importance of actors was different depending on the focus of centrality. Thus, a more influential actor in the same network in terms of Degree Centrality that focuses on the quantitative measure of actors connections turned to have a low influence in the Information centrality that focuses on the importance of an actor in the spread of information in a network. This was encouraging as it aligned itself logically to many other researchers [12] [41] who propose an amalgamation of the individually niched centralities into a socially acceptable aggregated influence of actors on networks. Our approach therefore, offered an extensive advantage in ensuring holistic decision making by implementing an algorithm that employs a multi-criteria approach, bringing all the centralities meaningfully under one umbrella. 
Applying our findings to decision making in the field of human resource management, hammering on the concept of efficiency in relation to employment and layoffs of labour, it is recommended that a social network analysis which adapts a multi-attribute decision-making approach that reflects both individual strength and weaknesses in totality for all aspect of social influences should be employed. This is justifiable from the results of our study that pitches the Closeness to Ideal Centrality as the most efficient among the assessed centralities in decision making. We recommend further studies addressing the relation between influential nodes and their impact on organizational innovation.

\section{Acknowledgements}

The authors are very grateful for the financial support from the National Science Foundation of China with Grant number 71371087

\section{Conflicts of Interest}

The authors declare no conflicts of interest regarding the publication of this paper.

\section{References}

[1] Kawai, N. (2015) Does Downsizing Really Matter? Evidence from Japanese Multinationals in the European Manufacturing Industry. The International Journal of Human Resource Management, 26, 501-519. https://doi.org/10.1080/09585192.2011.616525

[2] Bass, F.M. (2004) Comments on "A New Product Growth for Model Consumer Durables the Bass Model”. Management Science, 50, 1833-1840. https://doi.org/10.1287/mnsc.1040.0300

[3] Geroski, P.A. (2000) Models of Technology Diffusion. Research Policy, 29, 603-625. https://doi.org/10.1016/S0048-7333(99)00092-X

[4] Moglia, M., Cook, S. and McGregor, J. (2017) A Review of Agent-Based Modelling of Technology Diffusion with Special Reference to Residential Energy Efficiency. Sustainable Cities and Society, 31, 173-182. https://doi.org/10.1016/j.scs.2017.03.006

[5] Kogut, B. and Zander, U. (1992) Knowledge of the Firm, Combinative Capabilities, and the Replication of Technology. Organization Science, 3, 383-397. https://doi.org/10.1287/orsc.3.3.383

[6] Carol, W. (2008) Measuring Social Capital and Knowledge Networks. Journal of Knowledge Management, 12, 65-78. https://doi.org/10.1108/13673270810902948

[7] Klehe, U.-C., et al. (2011) Career Adaptability, Turnover and Loyalty during Organizational Downsizing. Journal of Vocational Behavior, 79, 217-229. https://doi.org/10.1108/13673270810902948

[8] Aşc1, H.B., Tan, F.Z. and Altıntaş, F. (2016) A Strategic Approach for Learning Organizations: Mental Models. Procedia-Social and Behavioral Sciences, 235, 2-11. https://doi.org/10.1016/j.sbspro.2016.11.002

[9] Birasnav, M., Chaudhary, R. and Scillitoe, J. (2019) Integration of Social Capital and Organizational Learning Theories to Improve Operational Performance. Global Journal of Flexible Systems Management, 20, 141-155. https://doi.org/10.1007/s40171-019-00206-9 
[10] Freeman, L.C. (1977) A Set of Measures of Centrality Based on Betweenness. Sociometry, 40, 35-41. https://doi.org/10.2307/3033543

[11] Stephenson, K. and Zelen, M. (1989) Rethinking Centrality: Methods and Examples. Social Networks, 11, 1-37. https://doi.org/10.1016/0378-8733(89)90016-6

[12] Li, M., et al. (2018) Identifying and Ranking Influential Spreaders in Complex Networks by Combining a Local-Degree Sum and the Clustering Coefficient. International Journal of Modern Physics B, 32, Article ID: 1850118. https://doi.org/10.1142/S0217979218501187

[13] Chuluun, T., Prevost, A. and Upadhyay, A. (2017) Firm Network Structure and Innovation. Journal of Corporate Finance, 44, 193-214.

https://doi.org/10.1016/j.jcorpfin.2017.03.009

[14] Landherr, A., Friedl, B. and Heidemann, J. (2010) A Critical Review of Centrality Measures in Social Networks. Business \& Information Systems Engineering, 2, 371-385. https://doi.org/10.1007/s12599-010-0127-3

[15] Bonacich, P. (2007) Some Unique Properties of Eigenvector Centrality. Social Networks, 29, 555-564. https://doi.org/10.1016/j.socnet.2007.04.002

[16] Tsai, W. (2001) Knowledge Transfer in Intraorganizational Networks: Effects of Network Position and Absorptive Capacity on Business Unit Innovation and Performance. Academy of Management Journal, 44, 996-1004. https://doi.org/10.2307/3069443

[17] Chou, S.Y. and Ramser, C. (2019) A Multilevel Model of Organizational Learning: Incorporating Employee Spontaneous Workplace Behaviors, Leadership Capital and Knowledge Management. The Learning Organization, 26, 132-145. https://doi.org/10.1108/TLO-10-2018-0168

[18] Dass, P.S. and Chelliah, S. (2019) Organizational Learning and Collective Human Capital Relationship with Firm Performance among MNEs in the Northern Region of Malaysia. In: Global Perspectives on Human Capital-Intensive Firms, IGI Global, Hershey, 176-197. https://doi.org/10.4018/978-1-5225-7426-2.ch008

[19] Kasemsap, K. (2019) Promoting Strategic Human Resource Management, Organizational Learning, and Knowledge Management in Modern Organizations. In: $A d$ vanced Methodologies and Technologies in Business Operations and Management, IGI Global, Hershey, 879-891. https://doi.org/10.4018/978-1-5225-7362-3.ch066

[20] Yoon, K.P. and Hwang, C.-L. (1995) Multiple Attribute Decision Making: An Introduction. Vol. 104, Sage Publications, Thousand Oaks.

https://doi.org/10.4135/9781412985161

[21] Jahanshahloo, G.R., Lotfi, F.H. and Izadikhah, M. (2006) Extension of the TOPSIS Method for Decision-Making Problems with Fuzzy Data. Applied Mathematics and Computation, 181, 1544-1551. https://doi.org/10.1016/j.amc.2006.02.057

[22] Lai, Y.-J., Liu, T.-Y. and Hwang, C.-L. (1994) TOPSIS for MODM. European Journal of Operational Research, 76, 486-500. https://doi.org/10.1016/0377-2217(94)90282-8

[23] Behzadian, M., et al. (2012) A State-of the-Art Survey of TOPSIS Applications. EXpert Systems with Applications, 39, 13051-13069. https://doi.org/10.1016/j.eswa.2012.05.056

[24] Zareie, A. and Sheikhahmadi, A. (2019) EHC: Extended H-Index Centrality Measure for Identification of Users' Spreading Influence in Complex Networks. Physica A: Statistical Mechanics and Its Applications, 514, 141-155. https://doi.org/10.1016/j.physa.2018.09.064 
[25] Deng, H., Yeh, C.-H. and Willis, R.J. (2000) Inter-Company Comparison Using Modified TOPSIS with Objective Weights. Computers \& Operations Research, 27, 963-973. https://doi.org/10.1016/S0305-0548(99)00069-6

[26] Boran, F.E., et al. (2009) A Multi-Criteria Intuitionistic Fuzzy Group Decision Making for Supplier Selection with TOPSIS Method. Expert Systems with Applications, 36, 11363-11368. https://doi.org/10.1016/j.eswa.2009.03.039

[27] Chou, Y.-C., et al. (2019) Assessing the Human Resource in Science and Technology for Asian Countries: Application of Fuzzy AHP and Fuzzy TOPSIS. Symmetry, 11, 251. https://doi.org/10.3390/sym11020251

[28] Du, Y., et al. (2014) A New Method of Identifying Influential Nodes in Complex Networks Based on TOPSIS. Physica A: Statistical Mechanics and Its Applications, 399, 57-69. https://doi.org/10.1016/j.physa.2013.12.031

[29] Amiri, M., et al. (2019) Prioritization of Flood Inundation of Maharloo Watershed in Iran Using Morphometric Parameters Analysis and TOPSIS MCDM Model. In: Spatial Modeling in GIS and $R$ for Earth and Environmental Sciences, Elsevier, Amsterdam, 371-390. https://doi.org/10.1016/B978-0-12-815226-3.00016-8

[30] Yong, D. (2006) Plant Location Selection Based on Fuzzy TOPSIS. The International Journal of Advanced Manufacturing Technology, 28, 839-844. https://doi.org/10.1007/s00170-004-2436-5

[31] Wang, T.-C. and Chang, T.-H. (2007) Application of TOPSIS in Evaluating Initial Training Aircraft under a Fuzzy Environment. Expert Systems with Applications, 33, 870-880. https://doi.org/10.1016/j.eswa.2006.07.003

[32] Jahanshahloo, G.R., Lotfi, F.H. and Izadikhah, M. (2006) An Algorithmic Method to Extend TOPSIS for Decision-Making Problems with Interval Data. Applied Mathematics and Computation, 175, 1375-1384. https://doi.org/10.1016/j.amc.2005.08.048

[33] Wang, Y.-M. and Elhag, T.M. (2006) Fuzzy TOPSIS Method Based on Alpha Level Sets with an Application to Bridge Risk Assessment. Expert Systems with Applications, 31, 309-319. https://doi.org/10.1016/j.eswa.2005.09.040

[34] de Andrade, R.L. and Rêgo, L.C. (2019) p-Means Centrality. Communications in Nonlinear Science and Numerical Simulation, 68, 41-55. https://doi.org/10.1016/j.cnsns.2018.08.002

[35] Ilyas, M.U. and Radha. H. (2011) Identifying Influential Nodes in Online Social Networks Using Principal Component Centrality. 2011 IEEE International Conference on Communications (ICC), Kyoto, 5-9 June 2011, 1-5. https://doi.org/10.1109/icc.2011.5963147

[36] Borgatti, S.P. (2005) Centrality and Network Flow. Social Networks, 27, 55-71. https://doi.org/10.1016/j.socnet.2004.11.008

[37] Borgatti, S.P. and Halgin, D.S. (2011) On Network Theory. Organization Science, 22, 1168-1181. https://doi.org/10.1287/orsc.1100.0641

[38] Rossi, A.G., et al. (2018) Network Centrality and Delegated Investment Performance. Journal of Financial Economics, 128, 183-206. https://doi.org/10.1016/j.jfineco.2018.02.003

[39] Liao, H., et al. (2017) Ranking in Evolving Complex Networks. Physics Reports, 689, 1-54. https://doi.org/10.1016/j.physrep.2017.05.001

[40] Muruganantham, A. and Gandhi, G.M. (2019) Framework for Social Media Analytics based on Multi-Criteria Decision Making (MCDM) Model. Multimedia Tools and Applications, 1-15. https://doi.org/10.1007/s11042-019-7470-2 
[41] Rizman Žalik, K. (2019) Evolution Algorithm for Community Detection in Social Networks Using Node Centrality. In: Bembenik, R., et al., Eds., Intelligent Methods and Big Data in Industrial Applications, Springer International Publishing, Cham, 73-87. https://doi.org/10.1007/978-3-319-77604-0_6

[42] Ren, G., et al. (2019) Analyzing the Topological Characteristic and Key Nodes of Chinese Air Sector Network. International Journal of Modern Physics B, 33, Article ID: 1950100. https://doi.org/10.1142/S0217979219501005 